\title{
Russian Mega-Cities: Some Current Structural-Functional Trends
}

\author{
Oleg N. Yanitsky* \\ PhD (Philosophy), professor, the Chief Researcher, Institute of Sociology of the Federal Research and Applied \\ Sociological Studies, the Russian academy of sciences. Address: 117218, Moscow, Russia
}

*Corresponding Author: Oleg N. Yanitsky, PhD (Philosophy), professor, the Chief Researcher, Institute of Sociology of the Federal Research and Applied Sociological Studies, the Russian academy of sciences. Address: 117218, Moscow, Russia

\begin{abstract}
The article analyzes the current trends and issues of the Russian mega-cities, and their relationships with a close and remote periphery. These cities are simultaneously concentrating a huge productive, scientific, political and cultural potential and worsening the situation of their close and remote periphery. The use of information technologies and networks accelerate the development of the mega-cities whereas their periphery gradually lags behind. The external appearance of the mega-city is changing very slowly, while a functional organization of these cities is changing permanently. The further the more the majority of the mega-cities' population considers them as a start-up for their carrier or as a jumping-off place for an emigration. A habitat structure of the above cities is changing as well: the estates of the rich are planned to situate in the central parts of the mega-cities while the majority of the poor will be gradually resettled to the periphery of the mega-cities. The estates of the rich will have their own gardens and all other necessary facilities whereas for the rest of the mega-cities residents the parks of a common use are planned. In sum, all residents of the mega-cities are socially and spatially disconnected, and their life is under double pressure: their structural-functional organization is permanently accelerated and transformed.
\end{abstract}

Keywords: center vs. periphery, globalization, information processes, mega-cities, networks, residents, structural-functional organization, urban planning, Russia

\section{The Drivers of Changes: A Situation AND NeW ChallengeS}

We are accustomed to comprehend our mega-cities as the human ant-hills concentrated in them thousand billions of its aborigines and newcomers. The theory of city-planning successfully developed in the Soviet times is now in decay. Recently so-called urban planners are mostly the developers who didn't take into account the major challenges of our times such as a transition toward a new, information-communication revolution (hereafter the ICR) as well as those deep and radical transformations under the transition to a market economy i.e. to the capitalist mode of production. At the same time, the agents of the above transformations and their environment gradually acquired a complex character. The process of the shaping of such integrated systems I call as the socioibiotechnical ones (hereafter the SBT-systems. See: Yanitsky, 2016).

Unfortunately, all heritage of the Soviet city-and-regional planning accumulated in the USSR in the second half of the XX century is practically forgotten. The developers who came to the forefront are only interested in getting profit and social prestige. Even a large-scale project of Moscow renovation accepted in the second decade of the XXI century hasn't been seriously substantiated and tested at public hearings. The Moscow city authorities successfully realize the project of replacing of fivestoried apartment houses by 40 and 80 stories sky-scrapers. A carefully-developed and tested the rules of urban planning, so-called 'The Norms and Rules of Constructive Work' developed in the 1960s are now neglected. The Muscovites have protested against so-called compressed habitat. The leading role of the Academy of architecture and construction of the USSR/RF and of the Moscow architectural institute has been irretrievably lost. The dialogue between the Big Science and the theory and practice of city planning has been stopped (Yanitsky, 2005, 2008, 2008a, 2009). Finally, the ties between a community of city planners and civil activists have been lost as well (Yanitsky, 2010, 2012). 
Accordingly, a project of a particular apartment house, estate or recreation zone usually designed by foreign architects or/and city planners came to the forefront. The developers and builders were usually Russian or from the Turkey. Private developers are usually indifferent to a long-term trends initiated by the ICR, they are concerned with getting a maximum profit now only, be it the apartment house, studio or any other project. The results of such 'urban politics' is well-seen on the examples of London, New York and many other foreign mega-cities in the West.

What is actually going on with Russian mega-cities under the transition toward the ICR or, using the image offered by M. Castells (2004), with the process of shaping of the 'Internet Galaxy'? First of all the ICR is changing a structure of the mega-cities in the minor degree while it transforming their structural-functional organization very substantially.

First, the information-communication structure of such cities is functioning independently of its planning structure because that structure is nearly totally independent from it. Actually, the structuralfunctional organization of the modern mega-city is divided on a 'material' and a 'virtual', and the last is defining the former because it all-embracing, much more quick functioning and easy accessible.

Second, the residents and the migrants using their gadgets are capable to orient both in the virtual and material urban space very quickly. That function of the virtual mega-city is very important, especially in the emergency cases.

Thirdly, by the use of the same gadgets a mega-city dweller or tourist is capable to maintain permanent communication with his/her relatives, friends, business-partners, etc. Or to look for a shelter, job medical aid or any other living facilities. Before the ICR it has been impossible or took a lot of time and money.

Fourthly, as M. Castells stated (2004), the Internet appearance assists in the diminishing social distance and social inequality between the rich and the poor. In this point I'm disagree with Castells because of the richness or wellbeing is offered to the person an unquestionable priorities.

Fifthly, under conditions of the ICR a man is permanently living in two social spaces, the material and virtual ones. If the first exert on him a redundant pressure he or she may escape from it living and working in the social networks i.e. plying the role of the bodies of social protection.

Sixthly, by means of global networks an individual may be informed about the coming natural disaster or about the existed the technological accident.

Seventhly, on the other hand, the information technologies bring to a man not only the goods and opportunities but exert on him many negative effects. First of all, I mean the hackers' attacks and other forms of interference into a person's life and behavior. Such attacks may be addressed to any productive and institutional structures that regulate a society and global life. Recently, such attacks are one of the new means of a market economy existence and development. At the same time an electro-magnetic radiation may cause negative effects on human health and behavior.

Eighthly, a permanent presence of the individual in the information environment sharply expanded the field of the mass-media activity and their opportunity to exert 'necessary' influence on the consciousness and behavior of global population. A shaping and permanently expanded of the consumer society sphere the liberal economists see as an indispensable prerequisite of the market economy existence.

The reverse side of the same coin is an accumulation of giant masses of industrial and human wastes in the megacities and around them. Ninthly, there is a transformation of the megacities from large industrial centers into the financial, retail and developmental places (mainly of the urban developers). It's indicative that like in the USA (I mean the Silicon Valley) the centers of production of information innovations are usually situated separately from the above cities. It should be noted that our country is still existed from the trade of natural resources.

Tenthly, a cumulative result of the abovementioned reasons is still growing gap between the megacities and all other types of human settlements, especially in remote Russia.

\section{AN ACCELERATION OF SOCIAL AND OTHER TRANSFORMATIONS}

Recently, it's hard to name the global society as a sustainable one. One of the reasons of that instability is the difference of the pace of ongoing transformations in various countries and regions under the pressure of inner and outer forces. 
Some of the societies still quickly developed, the others are much slower, still others are in decay, and some of them are disappeared from the historical arenas at all. The same is happened with the individuals and their groups. Today, the European Union is gradually turned into a 'union of different paces' with particular economic and social dynamics. It means that even the parts of the political whole and common market may develop with various paces. As to the global whole, it represents a conglomerate of interdepended mode of production and consumption limited by the resource deficit, specificity of a given political system and by many other factors including its geopolitical specificity.

Then, the pace of the development of a particular country is dependent on its specific mode of production that is on the development of the information-communication technologies. Therefore, the countries that are based on the mining (extracting) industry are developing much slower than the countries whose economy is based on the above advanced technologies. It signifies that if Russia wants to reach the USA and the EU it should make a 'triple jump': to restore its industrial power on the basis of new technologies, to raise sharply the wellbeing of the population, and to develop the information-communication industry by all possible means. The necessary prerequisite of such 'jump' are the investment into an accumulation of human and social capital.

Doing all that, we should to keep in mind not only the huge size of our country, its severe climate, and permanently changing a global geopolitical situation. Besides, some countries collaborate with Russia, while the others maintain the politics of sanctions. Anyhow, Russia is living in the global community of diverse speeds, and it have to be prepared to such diverse economic and political conditions.

Finally, the urban theorists and the developers are often forgotten that a various strata of the megacities' population adapts to permanent changes differently. My permanent included observations and interviews show that a great part of the megacities didn't want any changes in their everyday life. This statement is, first of all, concerned to the elderly who prefer to live in more or less constant living conditions.

Instead, the young and the teenagers who are living mainly in the mass-media are striving to live as fast as possible, in particular choosing very risky modes of living and actions. As to so-called middle class, its members are following the tempo-rhythms imposed on them by their working regime and the media.

\section{THE RELATIONSHIPS OF ECONOMIC, POLITICS, AND SOCIAL LIFE}

As a result of quick development of a resource-oriented economy, financial sector and mass-media plus of the development of consumer ideology, the amount of industrial enterprises in Russian megacities is steady diminished. The above processes resulted in the working class shrinking and fast development of the sphere of financial institutions. In parallel, an amount and diversity of the engaged in an administrative apparatus (both of all-Russian and city levels) is expanding.

Then, in Moscow and other megacities the largest universities sometimes coupled with the research institutions are concentrated. After then, all mass-media that are broadcasting over the world are situated. So the megacities are the national centers of social and political life. It should be taken into account; that in Russian megacities are concentrated many civil organization as the unions of the architects, musicians, cinematographers, environmentalists, and many others. These many civil organizations are taken a very little part in a shaping of urban politics and town-planning.

Therefore, as it regularly happened in the capitals of the developed and developing countries the mass meetings, rallies and protest actions are regularly happened. But the further the more such rallies and protest actions are based on the information network structures and therefore such gathering in the megacities are echoed in many other small cities and towns across the country.

As concerns to a regular social life as such, it's usually subjected to a numerous state laws and instructions produced by local authorities as well as to an established tempo-rhythms of the megacity life.

\section{THE RISKS OF THE MEGACITIES}

There are two kinds of the risks to which the megacities may be subjected. The former one is the outward risks, as the natural and technological ones (tornados, floods, forest fires and hackers' 
attacks, accidents with information-communication systems and many others). The latter one is the inward risks as a result of the geopolitical and of the megacities inward contradictions (the abovementioned unemployment, poverty, wastes' accumulation, etc.).

There is the third, to my mind, the most dangerous risk. The matter is that in the process of transition to the society based on information technologies some social institutions are lost their efficiency while the others are I the process of their construction and public approval only.

This risk has all-embracing scale and character. For example, the UN organization established after the WWII had created a new configuration of global superpowers and many other institutional structures. But nowadays the UN is often unable to resolve permanently emerging geopolitical issues whereas the two-sided agreements and multisided alliances are gaining power.

From the institutional viewpoint, the megacities are on the crossroads of global, national and megacities institutions. This situation generates a mighty risks and threats first of all in the sphere of an internet-communications that embraces the abovementioned all three levels. At the same time, this issue is acute for any megacity resident or corporation when, for example, a worker is shifting from an industrial labor to communication one i.e. to the level of interaction of a man-computer or a manglobal network.

The risk issue (or the challenges or threats) in relation of the human settlements is very complicated and multisided, and therefore its only description is needed a set of global research projects. It's sufficient to mention a problem of metabolism and shaping of the sociobiotechncal systems (hereafter the SBT-systems) because our world in quickly becoming more and more complicated and integrated. But the hybridization of our world is only the first step of integration of qualitatively different maters. Besides, there is an issue of a social metabolism as such.

But many natural and social sciences are remaining mono-disciplinary ones. I'm not neglect a necessity of a sociological or philosophical research as such. But in essence many social processes are complex ones in one way or another. More than that, these social processes are recently generated by various natural and technological processes like climatic changes and technological innovations.

The emergence and stimulation of some social processes by the other ones is worldwide case. The more the earth population is growing the stronger a struggle between particular states and communities for an access to deficit resources like a water, food and shelter. It follows that nature isn't only a variety of resources but a powerful social agent. Let me give some examples.

First and the most understandable one for anybody fact are the risks generated by a 'man-machine' system. The more it complicated, the more volume of information it is obliged to receive, store, rework and send for a request, and the more in this machine an amount of transmission links, the higher a probability of the errors in its functioning. There are a lot of examples of errors or accidents in cosmic flies, in the line between 'the earth-space' systems, etc.

Second tightly engaged with the first, is a combined a 'button-hand operation' complex systems of ruling. The more given system is complex the higher the probability of an error, and the system not always can identify who is guilty, a 'driver' or a smart machine as such.

Third, to think that the higher level of education of an operator the lower will be a probability of a risk is an error. The generation ' $Z$ ' or so-called 'button children' aren't accustomed to think, they usually act by simple listing of options. More than that, an illiterate terrorist is able to destroy any social and technical system constructed by highly-educated professionals. A difference between the illiterate hackers and the highly-educated professionals is effaced.

Therefore, fourth, from the 1950s and up to now world-known scientists and scholars warned humanity that not only the invention of nuclear weapons but the technical progress without its political and social comprehension is unavoidable potential risk. In those times the Pagwash movement for world peace and security has emerged but now that movement has come to naught, and the scientists-turned-political activists are divided much more than ever.

Fifth and well-seen: the first nuclear strike had been done on Japan large cities Hiroshima and Nagasaki.

And nowadays, the main target of any destructive strike including the hackers' attach will be the largest cities of the world. 


\section{THE STRUCTURAL-FUNCTIONAL TRANSFORMATIONS OF THE MEGACITIES}

As the leading US urbanist and sociologist S. Sassen (Sassen, 2000) has noted many times, a material and spatial structure of the megacities are transforming not seriously while their functions are undergo permanent transformations. It is a natural process since such cities are simultaneously included in productive and social life of many other cities and in the world system. In the process of development of the information technologies these transformations are permanently accelerated. In the end, these functional acceleration-and-transformations are becoming a norm of social life of the megacities.

In the final analysis, the above processes depend on the state politics. For example, the US president D. Trump draws attention of the American society and politics on the accelerated shaping of so-called the 'Rust Belt' of the country as a result of too intensive run of many national industries in the developing countries.

In Russia there is quite another problem. It is numerous small towns and other settlements in which lives approximately more than $25 \%$ of the Russian population. We should keep in mind that two biggest Russian megacities Moscow and St. Petersburg produce about 30\% of the GNP of the country. It means that the inhabitants of hundreds towns and smaller settlements are commuters of these two megacities in radius from 50 to 350 kilometers. And in the run of the Internet and social networks this trend will continue. It's mainly going on about a young people.

The megacities and their infrastructures deserve a permanent improvement of a protection system from various global risks, be it nuclear attack or a pandemia of an unknown virus.

My personal opinion is that the Russian megacities are still insufficiently prepared to a multisided (hybrid) strike from without. For example, the bomb-shelters in the megacities well equipped in and after the WWII are now used as the goods' stores for various shops. To buy an elementary respirator is sometimes is not an easy task. A mass teaching of the city dwellers how to render a first aid to the affected people is not still well-organized as well. At the same tine a mass festivals and other mass gathering in the megacities are potentially dangerous. To prepare the citizens to the critical situations and how to minimize their after-effects as it had been done more than 80 years ago is necessary.

Although, the above structural-functional trends that are simultaneously the social-spatial ones are already well-seen. The matter is that the megacities are quickly divided by a property and social ranking. The developers offered to design and build the estates for the rich and extra-rich in the very centers of the Russian megacities with the guards and full service. And the media are widely advertising such mode of 'reconstruction' of the old centers of the megacities. For example, in Moscow there are already the zones which are named as the 'golden miles.' At the same time the inhabitants of the old centers will be resettled to a periphery of the 'Big Moscow.' Such social-spatial transformation doesn't exclude the construction of small cottage settlements in the suburbs. This social-spatial differentiation is followed by the cultural one. The rich scornfully call the industrial workers and office workers as the 'salary workers' (literally as budgetniki) or simply the cattle.

In sum, the megacities is gradually extracted all people able to work, especially from the remote provinces. The matter is that together with these new urban residents and commuters the small provincial settlements lost their national and cultural specificity which is impossible to restore. The same processes are going on in all other regions of the country.

In Soviet times there were a special branch of urban planning named as a theory of the settlement. Nowadays, it totally disappeared there are the plans of a rehabilitation of small towns of a particular historical and cultural significance only. Plus there is a giant mass of the developers who are ready to build everywhere, but what exactly they are not interested. Therefore, developing the megacities there is a threat to lose an important part of our historical and cultural heritage.

\section{A MAN IN A MEGACITY}

British sociologist J. Urry (Urry, 2008) argued that the modern world is becoming totally mobile.

But as Z. Bauman $(2001,2004)$ clearly showed, such mobility isn't of a linear character. The rich and successful people are really constantly mobile while a great part of the world population isn't. This thesis is fully related to the megacities in question. What is the most important in our particular case? 
First, as it has been noted earlier, the modern man is living in two worlds, a material and virtual ones what gives him an opportunity to select i.e. to choose a kind and place of work, mode of spending a leisure time, friends and so on. But again: all depends on material and other possibilities. In Russian remote provinces the inhabitants of the villages and small settlements are tightly dependent on their housekeeping, kitchen-garden, childcare, etc. As well as these inhabitants are obliged to assist to the elderly, etc. Above all, the large families are strongly dependent on the state financial and social aid.

Second, a transition toward the digitally-based urban life will require a learning of the $\mathrm{ABC}$ digital literacy and so more mobility at least potentially. For example, the elderly and retired should learn to tame (govern) of his 'smart house.' It means that their space mobility may be reduces while a mental one will require new efforts and knowledges.

Thirdly, the mass resettlement of the salary workers (budgetniks, in Russian) into new suburban areas will necessarily destroy the established social ties and mode of mutual assistance. That destruction is already going in the process of the 'renovation' of the old centers of Moscow and forcefully involves the re-settlers in a long-term process of adaptation to the new living conditions.

Fourthly, judging by the developers' information the new flats is actually good but the re-settlers afraid to get (or buy) the new flats in the 40 and 80 -stored sky-scrapers. Besides, a time for travelling to the place of work and back to home will be much longer.

Fifthly, every year the migrants' flow coming to Moscow and St. Petersburg is growing. These people are not the urban dwellers in a usual sense of the word. Two weeks they are working in these capitals and then two weeks at home, for example in a small city or in a village some where about $100-350$ $\mathrm{km}$ aside from these megacities. They are the commuters the all year round, and therefore they are the marginal men and woman.

Sixthly, the life of those who work as the shift workers is much harder: very tense work, usually an extreme living conditions, periodical mobility, and so on and so forth. These two categories are considered the megacity as a place for the earning money but these people are not usually interested in historical and cultural heritage of the megacities.

Seventhly, the theme of the relationships of the megacities and their remote periphery is of a special importance, especially for the young. Some of them consider these cities as a starting point, the others look the means to become the megacities' permanent residents, still other consider these cities as the transit point for the emigration abroad, etc.

Therefore, though it sounds paradoxically, except the businessmen, traders and criminals the megacities are the most interesting to the foreign tourists and the visitors of the international sport events.

One should not forget that any megacity is a nutrient medium for a corruption, criminals, and shadow economy and for many other forms of an asocial activity. To my sorrow, a socio-ecological approach to the study of structural-functional organization of the megacities and the basic principles of it had been founded even in the 1920s by R. Park and E. Burgess in Russian sociology is not developed.

\section{THEORY AND PRACTICE OF MAKING OPEN SPACES}

Although I'm an urban sociologist and town planners in the past, I'm not a professional in this realm of town planning. Thus, I will further speculate as an ordinary inhabitant (budgetnik) of the megacity. If the abovementioned risks is possible to foresee but not to fully mitigate but in this particular sphere of making open spaces I'm the civil activist who about 40 years dealt with an environmental movement in the USSR/RF and abroad.

Firstly, undoubtedly the megacities' authorities and urban inhabitants should strive to expand the open areas in these cities. But it is undoubtedly as well that the making such spaces isn't a profitable matter for the business and developers.

Secondly, what is actually the profitable matter for the business and developers is designing and construction of the residential areas and all means of urban communication ranging from the underground lines and stations till new roads and the highways. But recently is a curious collision has emerged: the megacities' residents began gradually to reduce the use of private cars for the reason of the rising prices for fuel. Nevertheless, the communication systems are continued to develop. 
Thirdly, the city authorities are first of all interested in a realization of large-scale projects in this sphere of urban planning that is in designing and construction of large open space (parks with developed services and other facilities) while the inhabitants are first of all interested in a quite green spaces with the playground for the children near their apartments.

Fourthly, as it has been mentioned earlier, our life is speeding up permanently but in an everyday urban practice, especially in a repairing practice we don't see such acceleration. Here is the example. Near the apartment house in which I'm living he process of the replacing of the old steam-hit pipes took more than three years. These processes had been accompanied with everyday noise, dirty, and impossible of the private cars parking. And the most important is that our apartment house had been inaccessible for the emergency cars, fire brigades and their engines. And when all repairing works has been over, an open space had been restored in a three days. But except ourselves, i.e. the inhabitants, nobody assist us in the maintenance of our open space and its greenery whereas the estates of the rich will be cared by many special services. This imbalance should be surmounted.

\section{CONCLUSION AND DISCUSSION}

We are living now in an environment of numerous social, natural and technological challenges generated by the social processes and conflicts of a global and national scale and by uncontrolled development of new technologies, and first of all by the development of information-communication and biological technologies. To my mind, the risks generated by the new 'man-smart machine' systems are unavoidable. The more complex such hybrids the probability of a risk is higher.

Therefore, the construction in the mega-cities the open spaces and parks is the only a minor part of making these cities 'green.' Our problems are rooted in a tough struggle of global and national stakeholders for deficit resources and geopolitical domination. The notion 'green' contains first of all a criterion of natural, social and technological safety. A 'smart house', a 'smart city' are insufficient terms, if we don't disclose a social and natural sense of such terms. Then, of course, the rescue forces are absolutely necessary but without the volunteers and other civil society activists the mega-cities cannot exist.

Finally, the natural and social scientists together with urban planners should bother about a protection of historical and cultural heritage of small cities and other settlements. Otherwise, developing only the megacities a very essential part of a history and culture of our country will be irrevocably lost. The urban science and city planning are the complex disciplines therefore a complex interdisciplinary approach to city planning and construction has to be rehabilitated.

There are some specific methodological and theoretical issues that deserve special attention.

The matter is that the mega-cities are complex, highly-integrated hybrid systems. But they are still studied by mono-disciplinary methods. More than that, if these super-cities are differentiated by social and income principles it means that these cities are no more the systemic entities. Then in the XIX and $\mathrm{XX}$ centuries the factor of inclusion in the life of mega- cities had been considered as a fundamental one. But recently their constitutive factor isn't the inclusion to urban life but the inclusion into global networks and their nuclei. It's well-seen on the network communities in the business, power structures, scientific community, sport life and practically in all spheres of the mega-cities' life. Accordingly the members of such international network communities consider any place on the earth as a temporary point of his/her presence.

The mega-city authorities recognize this fact only in respect of international mass events (the Olympic Games and other sport events, conferences, tourists' flow and many other mass world-wide gathering. These authorities did their best in building new high-ways, roads, press communication, etc. But at the same time the network structure of ordinary people is subjected to many limitations. These intentions to limit interpersonal and small groups' contacts aren't coincided with a necessity of the development of personal ties and small groups' internet gatherings.

Unfortunately, the central and urban powers aren't notice these general tends of the inhabitants' dynamics of the megacities. And the more new rules and restrictions will be created, especially related to teenagers and students, the higher the risk of a degradation of the megacities in spite of welldeveloped urban infrastructure, the museums and exhibitions and other objects of a tourist visiting. 


\section{REFERENCES}

[1] Bauman Z. 2001. On Glocalization: Or Globalization for some, localization for some others, in: Bauman Z. The Bauman reader. Malden, MA: Blackwell Publishers Inc., pp. 298-311.

[2] Bauman Z. 2004. Wasted Lives. Modernity and its Outcasts. Cambridge, UK: Polity Press. 140 pp.

[3] Castells M. 2004. The Internet Galaxy. Reflections on the Internet, Business, and Society. Oxford: Oxford University Press. 292 pp.

[4] Sassen S. Territory and Territoriality in the Global Economy, International Sociology, 2000, Vol. 15 (2): 372-393.

[5] Urry J. 2008. Mobilities. Cambridge: Polity Press. 275 pp.

[6] Yanitsky O. 2005. Dialogue between Science and Society. Social Sciences. A Quarterly Journal of the Russian Acad. of Sciences Vol. 36, No 2, Pp.78-90.

[7] Yanitsky O., ed. 2008. Modernization in Russia: Challenges to Research and Education. Institute of Sociology: Moscow.

[8] Yanitsky O. 2008a. Training + Research (First Experience with Tutorship). In: Yanitsky O., ed. Modernization in Russia: Challenges to Research and Education. Institute of Sociology: Moscow: 3-12.

[9] Yanitsky O. 2009. The Shift of Environmental Debates in Russia, Current Sociology 57 (6): 747-766.

[10] Yanitsky O. 2010. Russian Environmentalism. The Yanitsky Reader. Moscow: TAUS.

[11] Yanitsky, O. 2012. A Primary Eco-Structure: The Concept and its Testing. Social Analysis, Vo.2 No 2: 7-24.

[12] Yanitsky O. 2016. Sotsiobiotechnical systems: A new view on man-nature relations. Sotsiologicheskaya nauka i sotsial'naya praktika, Vol. 4, no 3: 5-22 (in Russ.).

[13] Available at: http://manuscript.sciknow.org/uploads/ojssr/pub/ojssr_140963345.pdf

Citation: Oleg N. Yanitsky. "Russian Mega-Cities: Some Current Structural-Functional Trends" International Journal of Research in Sociology and Anthropology (IJRSA), vol 5, no. 4, 2019, pp. 33-40. doi: http://dx.doi.org/10.20431/2454-8677.0504004.

Copyright: (C) 2019 Authors. This is an open-access article distributed under the terms of the Creative Commons Attribution License, which permits unrestricted use, distribution, and reproduction in any medium, provided the original author and source are credited. 